Check for updates

Cite this: RSC Adv., 2018, 8, 243

Received 1st November 2017 Accepted 7th December 2017

DOI: $10.1039 / c 7 r a 12009 e$

rsc.li/rsc-advances

\section{Shape-selective methylation of naphthalene with methanol over SAPO-11 molecular sieve modified with hydrochloric acid and citric acid}

\author{
Xiaoxiao Wang, (D) ${ }^{a}$ Zhenmin Liu, ${ }^{a}$ Fang Guo, ${ }^{b}$ Yingchun Wang, ${ }^{a}$ Xianxian Wei, ${ }^{c}$ \\ Peng Li, ${ }^{a}$ Yongbing Xue, ${ }^{a}$ Yuanyang Wang, ${ }^{* a}$ Shaoqing Guo*c and Yue Yu ${ }^{d}$
}

Herein, a series of SAPO-11 molecular sieves were modified by citric acid and hydrochloric acid. They were characterized by ICP, XRD, SEM, $\mathrm{N}_{2}$ adsorption-desorption, $\mathrm{NH}_{3}-\mathrm{TPD},{ }^{29} \mathrm{Si}$ MAS NMR, and Py-IR and evaluated by the methylation of naphthalene with methanol to 2,6-dimethylnaphthalene (2,6-DMN). According to the XRD results, hydrochloric acid at a high concentration not only removed extraframework aluminum but also deleted framework silicon; this resulted in the formation of crystal defects. $\mathrm{N}_{2}$ adsorption-desorption results showed that all the samples possessed micropores and secondary mesopores. The SAPO-11 sample modified with $4 \mathrm{~mol} \mathrm{~L}^{-1}$ hydrochloric acid for 30 min exhibited the largest secondary mesopore size distributions. $\mathrm{NH}_{3}-\mathrm{TPD}$ and ${ }^{29} \mathrm{Si}$ MAS NMR showed that hydrochloric acid at a high concentration could eliminate more acid sites. SAPO-11 modified with 4 mol L $\mathrm{L}^{-1}$ hydrochloric acid for 30 min presented high catalytic performance for the methylation of naphthalene; this was mainly attributed to the amount of secondary mesopores in the SAPO-11 molecular sieves.

\section{Introduction}

2,6-Dimethylnaphthalene (2,6-DMN) is an important intermediate in the synthesis of polyethylene naphthalene dicarboxylate (PEN). Compared with polyethylene terephthalate (PET), PEN has good thermal and chemical stability as well as mechanical properties in addition to its excellent properties as a gas barrier; this leads to its wide application in electronic components, insulation materials, food containers, aviation, and so on. However, high cost and low availability of 2,6-DMN restrict the large production and commercialization of PEN at present. $^{1,2}$

Currently, 2,6-DMN is mainly produced by BP-Amoco through four-step reactions from $o$-xylene and butadiene. However, this synthetic route is environmentally unfriendly and expensive; this greatly limits its application in industry. To reduce the high cost of production of 2,6-DMN, a process of preparation of 2,6-DMN by the methylation of naphthalene or 2methylnaphthalene over molecular sieve is proposed, which is a simple and desirable synthetic route. However, the products of methylation are very complex mixtures, and

\footnotetext{
${ }^{a}$ Taiyuan University of Science and Technology, School of Chemical and Biological Engineering, Taiyuan 030024, PR China.E-mail: yywangs@163.com

${ }^{b}$ Jin Zhong University, College of Chemistry and Chemical Engineering, Yuci 030619, PR China

${ }^{c}$ Taiyuan University of Science and Technology, College of Environment and Safety, Taiyuan 030024, PR China. E-mail: guosq@sxicc.ac.cn

${ }^{d}$ Lin Yi Academy of Technology Cooperation and Application, Linyi 276000, PR China
}

dimethylnaphthalene (DMN) has 10 different isomers with similar boiling point. It is very difficult to separate 2,6-DMN and 2,7-DMN as the difference between their boiling points is only $0.3{ }^{\circ} \mathrm{C}$. Therefore, it is necessary to find a molecular sieve with high selectivity for 2,6-DMN at acceptable conversion of naphthalene or 2-methylnaphthalene to 2,6-DMN.

Recently, the methylation of naphthalene or 2-methylnaphthalene with methanol has been studied over several molecular sieve catalysts such as ZSM-5, HY, ZSM-12, and SAPO-11..$^{3-6}$ Among these molecular sieves, SAPO-11 has been proven to be effective with high catalytic activity and selectivity for 2,6-DMN in the methylation of NAPH., ${ }^{7,8}$ The SAPO-11 molecular sieve is a one-dimensional pore molecular sieve with pore openings of $0.39 \mathrm{~nm} \times 0.64 \mathrm{~nm},{ }^{9,10}$ which are between the pore size of largepore and medium-pore molecular sieves, making it an interesting material for catalytic cracking, reforming, and alkylation. The pore size of SAPO-11 is larger than $0.60 \mathrm{~nm}$; thus, SAPO-11 can effectively sieve the products of naphthalene methylation. In addition, SAPO-11 showed excellent resistance to deactivation by carbonaceous deposits due to its one-dimensional pores. ${ }^{11}$ Hence, SAPO-11 is considered to be the most promising catalyst for the selective methylation of naphthalene to 2,6-DMN.

Although SAPO-11 has shown high catalytic performance in the methylation of naphthalene, several modification techniques can further improve the catalytic performance of the SAPO-11 molecular sieve catalyst. Acid dealumination is an important method to improve the catalytic performance of molecular sieves through the modification of pore structure and 
surface acid properties and leads to high hydrothermal stability. Park et al. reported that HM after steam treatment at $550{ }^{\circ} \mathrm{C}$ followed by acid leaching exhibited high and steady conversion of $40 \%$; the ratio of $2,6-/ 2,7-\mathrm{DMN}$ was 2.4 in $5 \mathrm{~h}$ of time on stream. ${ }^{12}$ Bai et al. reported that dealumination of HZSM-12 with hydrochloric acid and citric acid has different effects on the pore structure, acidic properties, and catalytic activity. Hydrochloric acid eliminates the strong and weak acid sites simultaneously without destroying the skeleton structure of the molecular sieve and improving the catalytic performance and stability. ${ }^{13}$ Najar et al. studied the effect of acid dealumination on the physico-chemical properties of $\mathrm{Y}$ molecular sieves and showed that all acids were effective in removing $\mathrm{Al}$ from the framework. Moreover, the extra-framework Al extraction from the lattice was dependent on the nature and concentration of the acid. ${ }^{14}$ However, the studies about the influence of acid dealumination on the catalytic performance of SAPO-11 have not been reported to date for the methylation of naphthalene.

In this study, a series of SAPO-11 molecular sieves were modified by citric acid and hydrochloric acid to investigate the influence of acid-dealumination on the physicochemical and catalytic performances of SAPO-11 for the methylation of naphthalene. The physicochemical properties of SAPO-11 molecular sieves and dealuminated SAPO-11 molecular sieves were characterized by ICP, XRD, SEM, FT-IR, $\mathrm{N}_{2}$ adsorptiondesorption, $\mathrm{NH}_{3}$-TPD, Py-IR, and ${ }^{29} \mathrm{Si}$ MAS NMR, and the catalytic performances of these samples were studied for the methylation of naphthalene with methanol.

\section{Experimental}

\subsection{Catalyst preparation}

SAPO-11 was synthesized by hydrothermally crystallizing a sol-gel mixture with a composition of $1.0 \mathrm{Al}_{2} \mathrm{O}_{3}: 1.0 \mathrm{P}_{2} \mathrm{O}_{5}: 0.6 \mathrm{SiO}_{2}: 1.2 \mathrm{DPA}: 49 \mathrm{H}_{2} \mathrm{O}$. The final crystallization temperature of $180{ }^{\circ} \mathrm{C}$ and crystallization time of 20-28 h were employed. The products were washed with distilled water, then dried at $120{ }^{\circ} \mathrm{C}$ for $5 \mathrm{~h}$, and calcined at $600{ }^{\circ} \mathrm{C}$ for $4 \mathrm{~h}$. The obtained sample was SAPO- 11 .

Dealumination was performed by acid leaching $5 \mathrm{~g}$ of SAPO11 mixed with $150 \mathrm{~mL}$ solution of critic acid or hydrochloric acid at the reflux temperature. The samples treated with $1 \mathrm{~mol} \mathrm{~L}^{-1}, 4 \mathrm{~mol} \mathrm{~L}^{-1}$, and $8 \mathrm{~mol} \mathrm{~L}^{-1}$ hydrochloric acid for 30 min were denoted as HClS1, HClS2, and HClS3, respectively. Similarly, samples modified with $1 \mathrm{~mol} \mathrm{~L}^{-1}, 4 \mathrm{~mol} \mathrm{~L}^{-1}$, and $8 \mathrm{~mol} \mathrm{~L}^{-1}$ critic acid for $30 \mathrm{~min}$ were labeled as CAS1, CAS2, and CAS3, respectively. The obtained molecular sieve samples were washed with water, dried at $120^{\circ} \mathrm{C}$ for $12 \mathrm{~h}$, and then calcined at $550{ }^{\circ} \mathrm{C}$ for $4 \mathrm{~h}$.

\subsection{Catalyst characterization}

The elemental compositions of the samples were determined by inductively coupled plasma-optical (ICP) emission spectroscopy (Perkin-Elmer ICP OPTIMA-3000).

$\mathrm{X}$-ray powder diffraction (XRD) analysis was performed using a Rigaku D/max rB X-ray diffractometer. Diffraction patterns were obtained recorded with $\mathrm{Cu} \mathrm{K} \alpha$ radiation at $40 \mathrm{kV}$ and 100 $\mathrm{mA}$ in the scan range between $5^{\circ}$ and $50^{\circ}$ to identify the phase structure of the sample.

Scanning electron microscopy (SEM) was performed using a LEO-435VP scanning electron microscope operated at $20 \mathrm{kV}$ and 50 PA.

Fourier transform infrared (FTIR) spectroscopy spectra of the samples were obtained using a Nicolet 380 FTIR spectrometer.

The textural properties of the samples were derived from $\mathrm{N}_{2}$ adsorption-desorption measurements conducted using a Micromeritics Tristar 3000. In each case, the sample was outgassed under vacuum at $300{ }^{\circ} \mathrm{C}$ for $3 \mathrm{~h}$ before $\mathrm{N}_{2}$ adsorption. The specific surface area was calculated according to the BET method, and the volume of pores of the sieve was obtained by $t$ plot analysis of the adsorption isotherm.

The acidity was examined by temperature programmed desorption of ammonia ( $\mathrm{NH}_{3}$-TPD) technique, which was carried out in a flow system with a thermal conductivity detector. All samples were preheated from room temperature to $500{ }^{\circ} \mathrm{C}$ in an argon flow and kept at $500{ }^{\circ} \mathrm{C}$ for $1 \mathrm{~h}$; these samples were then saturated with $\mathrm{NH}_{3}$ by a flowing stream of $\mathrm{NH}_{3} / \mathrm{Ar}$ at $40{ }^{\circ} \mathrm{C}$ for $5 \mathrm{~min}$. Evacuation at $40{ }^{\circ} \mathrm{C}$ for $40 \mathrm{~min}$ was carried out to remove physically adsorbed $\mathrm{NH}_{3}$; then, the catalyst was heated to $600{ }^{\circ} \mathrm{C}$ at a linear heating rate of $10^{\circ} \mathrm{C} \mathrm{min}^{-1}$, and the detector signal of $\mathrm{NH}_{3}$ was determined.

IR spectra of adsorbed pyridine (Py-IR) were obtained using a Nicolet-510P apparatus. Prior to pyridine adsorption, the calcined samples were pressed into thin wafers and evacuated in situ under vacuum at $300{ }^{\circ} \mathrm{C}$ for $2 \mathrm{~h}$ and then cooled down to room temperature; pyridine was then dosed onto samples until saturation; finally, the system was evacuated at different temperatures, and the adsorbed pyridine was measured by IR spectroscopy.

${ }^{29}$ Si MAS NMR experiments were carried out using a Varian infinity-plus $300 \mathrm{NMR}$. All ${ }^{29} \mathrm{Si}$ MAS NMR spectra were obtained at $79.5 \mathrm{MHz}$ using $2.0 \mu$ s pulse with $3.0 \mathrm{~s}$ recycle delay and 7120 scans.

\subsection{Catalyst evaluation}

Experiments were performed in a continuous flow fixed-bed reactor equipped with a stainless-steel tube (with $20 \mathrm{~mm}$ diameter and $600 \mathrm{~mm}$ length). Then, $2.5 \mathrm{~g}$ of 20-40 mesh molecular sieve catalysts were loaded onto this reaction tube. The reaction mixture was fed into the reactor by a quantity measuring pump, and the pressure was maintained by $\mathrm{N}_{2}$. The weight hourly space velocity (WHSV) of naphthalene was $0.19 \mathrm{~h}^{-1}$ in all the experiments. The reaction temperature was $400{ }^{\circ} \mathrm{C}$, and the liquid reactants naphthalene, methanol, and mesitylene (solvent) in a molar ratio of $1: 5: 3.5$ were preheated before passing them to the reactor. The reaction products were analyzed by gas chromatography (GC9560) using a Beta-Dex 120 capillary column. Conversion of naphthalene was calculated as follows:

$$
\text { Naphthalene conversion }(\%)=\left(\frac{n_{\mathrm{N}, 0}-n_{\mathrm{N}}}{n_{\mathrm{N}, 0}}\right) \times 100 \%
$$


where $n_{\mathrm{N}, 0}$ and $n_{\mathrm{N}}$ are the molar percentage of naphthalene before and after the reaction. The product distribution includes the corresponding molar percentages of ethylnaphthalene (EN), methylnaphthalene (MN), dimethylnaphthalene (DMN), and trimethylnaphthalene (TMN) in the total product mixture.

The selectivity of $2,6-\mathrm{DMN}$ is the corresponding molar percentage in the sum of all DMN isomers. 2,6-/2,7-DMN stands for the molar ratio of 2,6-DMN to 2,7-DMN. 2,6-DMN yield = (naphthalene conversion $\times 2,6-\mathrm{DMN}$ distribution)/100\%.

\section{Results and discussion}

\subsection{Characterization of catalysts}

3.1.1 XRD and ICP. The XRD patterns of untreated and acid-treated SAPO-11 samples are shown in Fig. 1. The bulk composition and relative crystallinity of the samples are shown in Table 1. As shown in Fig. 1, the characteristic peaks of the SAPO-11 phase $\left(2 \theta=8.15^{\circ}, 9.40^{\circ}, 13.20^{\circ}\right.$, and $\left.15.57^{\circ}\right)$ are observed for all the acid-dealuminated SAPO-11 samples, which are identical to those of the pure SAPO-11 material. ${ }^{15}$ This suggests that acid dealumination does not destroy the AEL topology of the SAPO-11 molecular sieves.

Table 1 clearly shows that the relative crystallinity of SAPO-11 molecular sieves decreases as the concentration of $\mathrm{HCl}$ and CA increases because of the formation of amorphous phases during dealumination that do not diffuse-off from the channels. In addition, the $\mathrm{Si} / \mathrm{Al}$ ratio of SAPO-11 modified by CA increases as the concentration of citric acid increases. This is probably due to the removal of extra-framework aluminum of pure SAPO11. The Si/Al ratios in HClS1 and HClS2 samples are also larger than those in SAPO-11, but the Si/Al ratio in the HClS3 samples is smaller than that in HClS2. This is because the acid concentration of HClS3 is very high such that it not only removes extra-framework aluminum but also deletes framework silicon; this results in the formation of crystal defects. It has been reported in literature that hydrolysis of silicon bonds occurs in the case of $6 \mathrm{~mol} \mathrm{\textrm {L } ^ { - 1 }}$ nitric acid. ${ }^{16}$ Thus, our
Table 1 Compositional and structural characteristics of SAPO-11 and SAPO-11 molecular sieves treated with acids

\begin{tabular}{llll}
\hline Sample & Treatment method & $\mathrm{Si} \mathrm{Al}^{a}$ & Relative crystallinity (\%) \\
\hline SAPO-11 & Parent & 76 & 100 \\
HClS1 & $1 \mathrm{~mol} \mathrm{~L}^{-1}, \mathrm{HCl}, 30 \mathrm{~min}$ & 87 & 91 \\
HClS2 & $4 \mathrm{~mol} \mathrm{~L}^{-1}, \mathrm{HCl}, 30 \mathrm{~min}$ & 94 & 84 \\
HClS3 & $8 \mathrm{~mol} \mathrm{~L}^{-1}, \mathrm{HCl}, 30 \mathrm{~min}$ & 80 & 78 \\
CAS1 & $1 \mathrm{~mol} \mathrm{~L}^{-1}, \mathrm{CA}, 30 \mathrm{~min}$ & 79 & 94 \\
CAS2 & $4 \mathrm{~mol} \mathrm{~L}^{-1}, \mathrm{CA}, 30 \mathrm{~min}$ & 85 & 82 \\
CAS3 & $8 \mathrm{~mol} \mathrm{~L}^{-1}, \mathrm{CA}, 30 \mathrm{~min}$ & 89 & 73
\end{tabular}

${ }^{a}$ By ICP.

experimental results are consistent with findings reported in the literature.

3.1.2 SEM. SEM results of untreated and acid-treated SAPO11 samples are presented in Fig. 2(a-g). From Fig. 2, it is evident that the bulk of acid-treated SAPO-11 samples is slightly modified as compared to that of the untreated SAPO-11; moreover, HClS3 is corroded and cracked due to severe dealumination accompanied by desilication.

3.1.3 FT-IR. Fig. 3 shows the FTIR spectra of untreated and acid-treated SAPO-11 samples. According to the literature, ${ }^{17}$ all peaks are assigned as follows: $1121 \mathrm{~cm}^{-1}$ arising from the asymmetric stretching vibration of inner tetrahedra; $706 \mathrm{~cm}^{-1}$ ascribed to the symmetric stretching vibration of inner tetrahedra; $630 \mathrm{~cm}^{-1}$ and $556 \mathrm{~cm}^{-1}$ due to deformation vibration of the four-membered ring and the deformation vibration of sixmembered ring, respectively. The $417 \mathrm{~cm}^{-1}$ corresponds to the deformation vibration of inner tetrahedra. From here we can see that the positions of peaks of all acid-treated SAPO-11 samples are in good agreement with those of SAPO-11.

3.1.4 $\mathbf{N}_{2}$ adsorption-desorption characterization. Table 2 presents the pore structure parameters of untreated and acidtreated SAPO-11 samples. As seen in Table 2, the mesopore volume of acid-treated SAPO-11 samples (except for HClS3) is
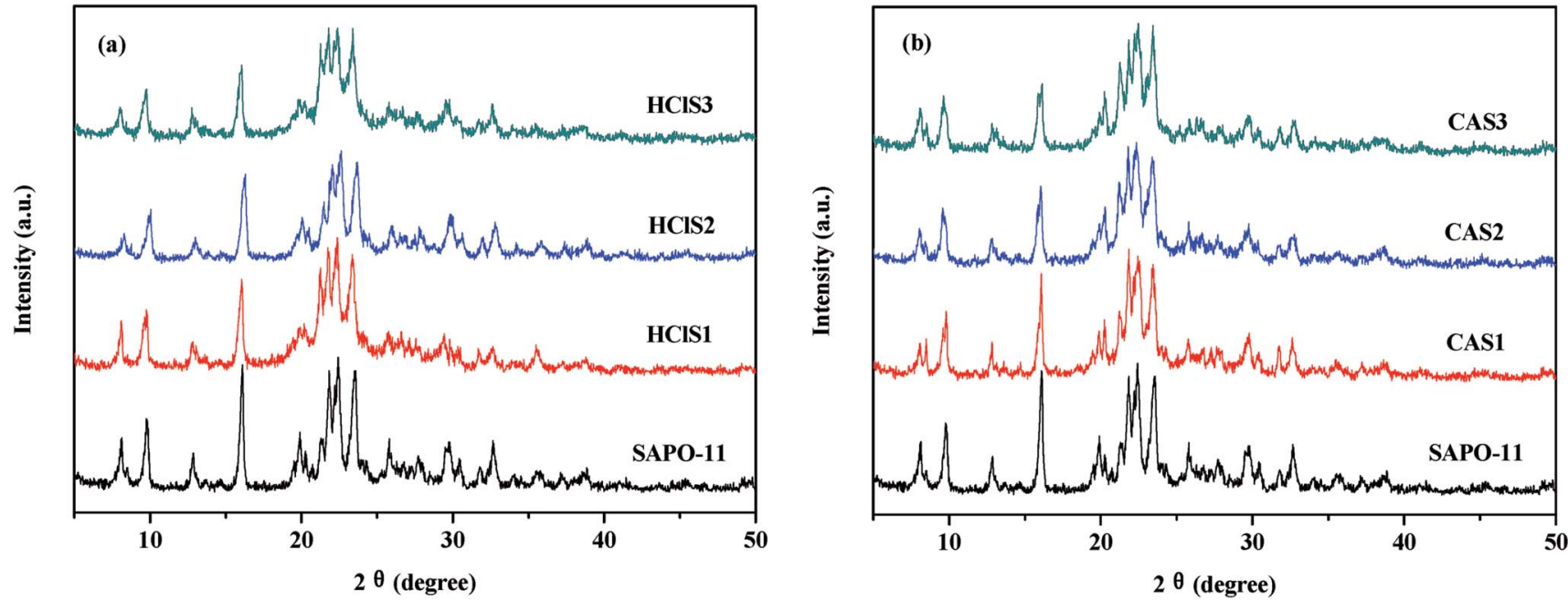

Fig. 1 XRD patterns of SAPO-11 and SAPO-11 molecular sieve samples treated with $\mathrm{HCl}(\mathrm{a})$ and CA (b). 

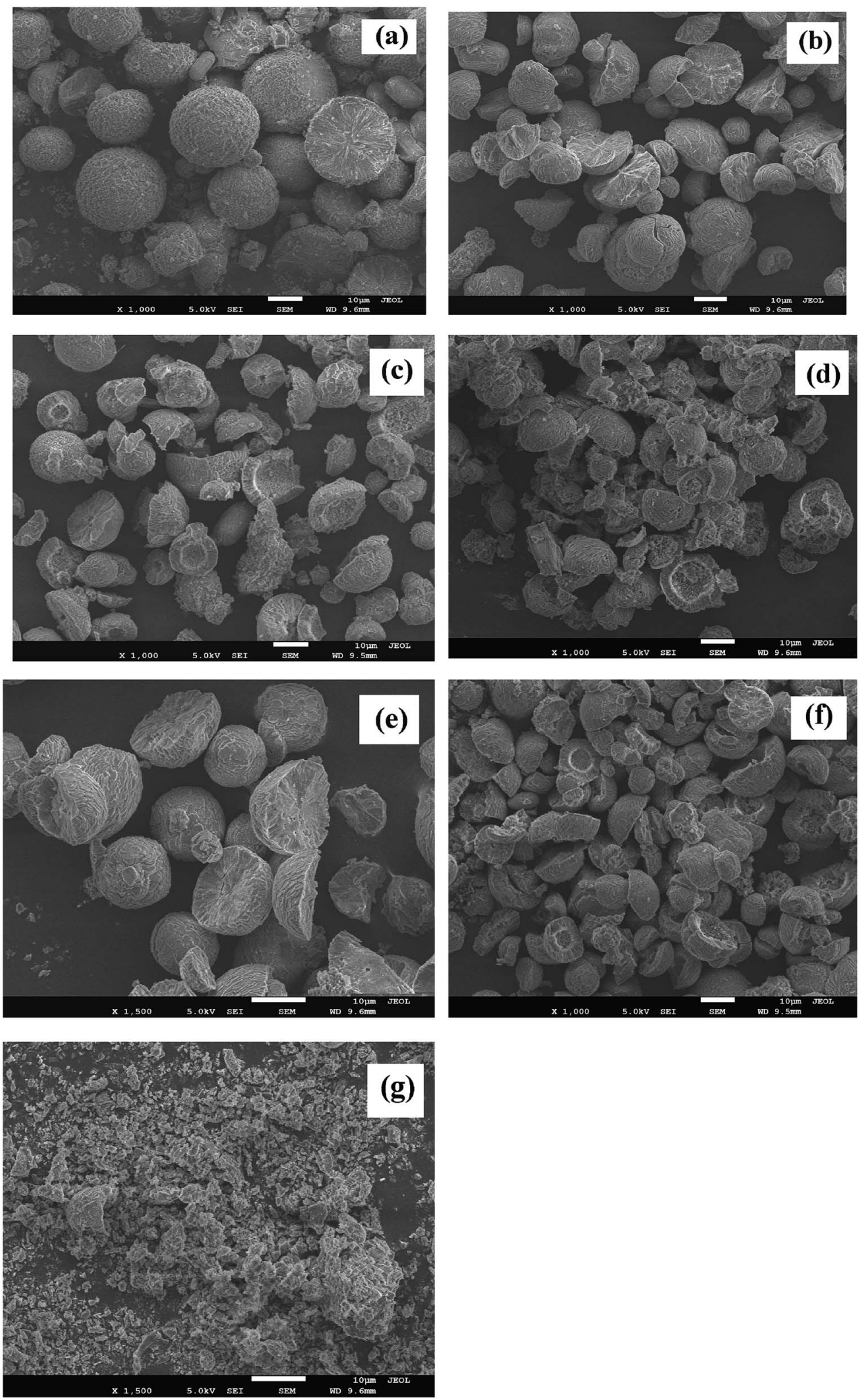

Fig. 2 SEM images of SAPO-11 and SAPO-11 molecular sieves treated with acids. (a) SAPO-11, (b) HCIS1, (c) HCIS2, (d) HCIS3, (e) CAS1, (f) CAS2, and (g) CAS3.

larger than that of SAPO-11 as $\mathrm{HCl}$ and $\mathrm{CA}$ can remove aluminum oxide species that block the mesopores without the destruction of the SAPO-11 framework. Table 2 shows that the mesopore volume of HClS2 is the largest of all untreated and acid-treated SAPO-11 samples. In addition, the surface area and pore volume of the acid-treated SAPO-11 samples (except for 


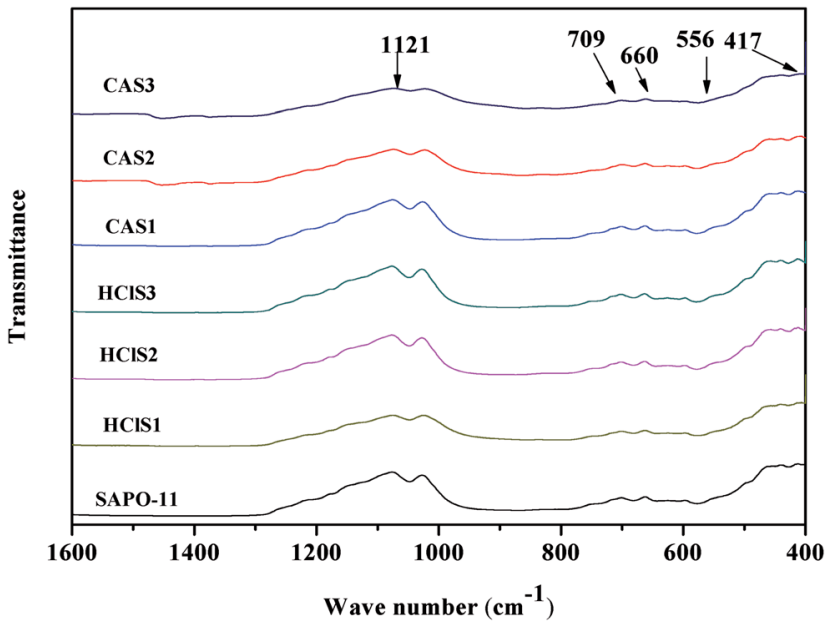

Fig. 3 FTIR spectra of SAPO-11 and SAPO-11 molecular sieves treated with acids.

Table 2 Pore structure parameters of SAPO-11 and SAPO-11 molecular sieves treated with acids

\begin{tabular}{llllllll}
\hline & \multicolumn{3}{c}{ Surface area, $\mathrm{m}^{2} \mathrm{~g}^{-1}$} & & \multicolumn{2}{c}{ Pore volume, $\mathrm{cm}^{3} \mathrm{~g}^{-1}$} \\
\cline { 2 - 3 } Sample & BET & Micropore & External & & Total & Micropore & Mesopore \\
\hline SAPO-11 & 149.6 & 96.6 & 53 & & 0.116 & 0.053 & 0.063 \\
HClS1 & 155.2 & 91.2 & 64 & & 0.121 & 0.051 & 0.070 \\
HClS2 & 162.2 & 94.2 & 68 & & 0.132 & 0.053 & 0.079 \\
HClS3 & 142.8 & 82.8 & 58 & & 0.097 & 0.042 & 0.055 \\
CAS1 & 151.6 & 91.6 & 60 & & 0.118 & 0.053 & 0.065 \\
CAS2 & 154.3 & 91.3 & 63 & & 0.120 & 0.052 & 0.068 \\
CAS3 & 157.4 & 92.4 & 65 & & 0.123 & 0.052 & 0.071
\end{tabular}

HClS3) is larger than that of SAPO-11. This is because framework alumina and extra-framework alumina can escape from the channels during the acid treatment process. However, compared with the case of SAPO-11, the surface area, pore volume, and mesopore volume of HClS3 markedly decreased because the amorphous silica in SAPO-11 formed nonframework materials during the acid treatment process that blocked the micropore channels and led to the decreased surface area, pore volume, and mesopore volume.

The $\mathrm{N}_{2}$ adsorption-desorption isotherms of SAPO-11, HClS2, HClS3, and CAS3 are shown in Fig. 4. The typical $\mathrm{N}_{2}$ adsorptiondesorption isotherms of as-synthesized samples are of the IV isotherm type according to the IUPAC classification. High adsorption of $\mathrm{N}_{2}$ occurred in the low relative pressure range, and obvious hystereses are detected, suggesting the existence of micropores and secondary mesopores in untreated and acidtreated SAPO-11 samples. Hysteresis between adsorption and desorption branches can be observed at medium relative pressure (0.3-1.0) for all samples; this demonstrates the presence of a large number of secondary mesopores. Fig. 4 shows that the secondary mesopore size distributions decreases in the following order: HClS2 > CAS3 > SAPO-11 > HClS3.

3.1.5 $\mathrm{NH}_{3}$-TPD and Py-IR. $\mathrm{NH}_{3}$-TPD is frequently used to determine the number and strength of the acid sites in catalysts. The $\mathrm{NH}_{3}$-TPD results of SAPO-11, HClS2, HClS3, and CAS3

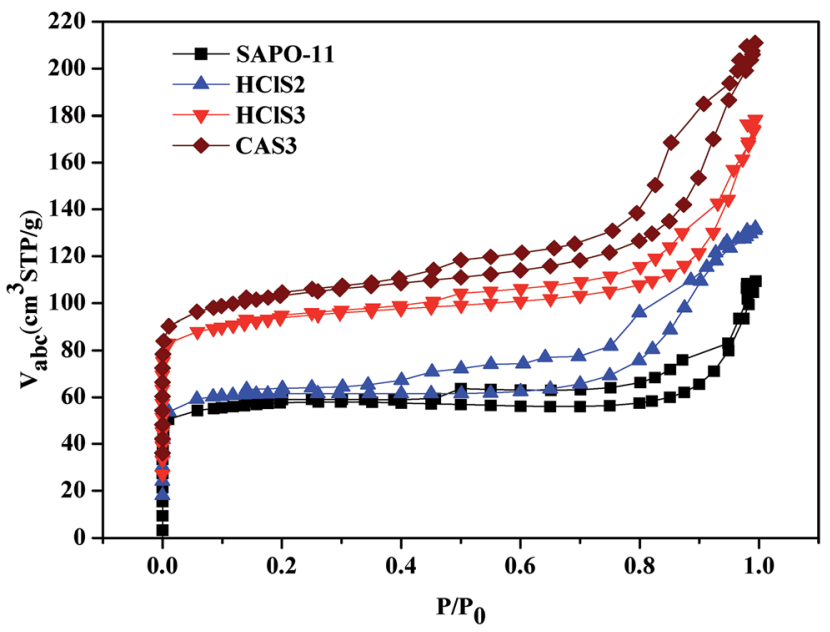

Fig. $4 \mathrm{~N}_{2}$ adsorption-desorption isotherms of SAPO-11, HCIS2, HCIS3, and CAS3.

are presented in Fig. 5. There is only one distinct region at $230{ }^{\circ} \mathrm{C}$ for all the samples, which indicates that weak acid sites are dominant in SAPO-11, HClS2, HClS3, and CAS3. Fig. 5 shows that the acid strength of all the samples is qualitatively similar. The total acid number of the samples decreases in the following order: CAS3 > HClS2 > SAPO-11 > HClS3. HClS2 has a larger number of acid sites than SAPO-11 because hydrochloric acid at a low concentration removes the aluminum oxide species; this blocks the micropores; therefore, more acid sites are exposed. The number of acid sites of HClS3 are lower as compared to those of SAPO-11; this indicates that hydrochloric acid at a high concentration eliminates more acid sites. Compared to other samples, CAS3 has most number of acid sites; this is related to the concentration of critic acid.

The surface acidity of SAPO-11, HClS2, HClS3, and CAS3 was determined by in site Py-IR technique. Usually, the bands at approximately $1450 \mathrm{~cm}^{-1}$ and $1621 \mathrm{~cm}^{-1}$ are assigned to Lewis acid sites, whereas the bands at around $1540 \mathrm{~cm}^{-1}$ and $1639 \mathrm{~cm}^{-1}$ are assigned to Brönsted acid sites. In addition, the

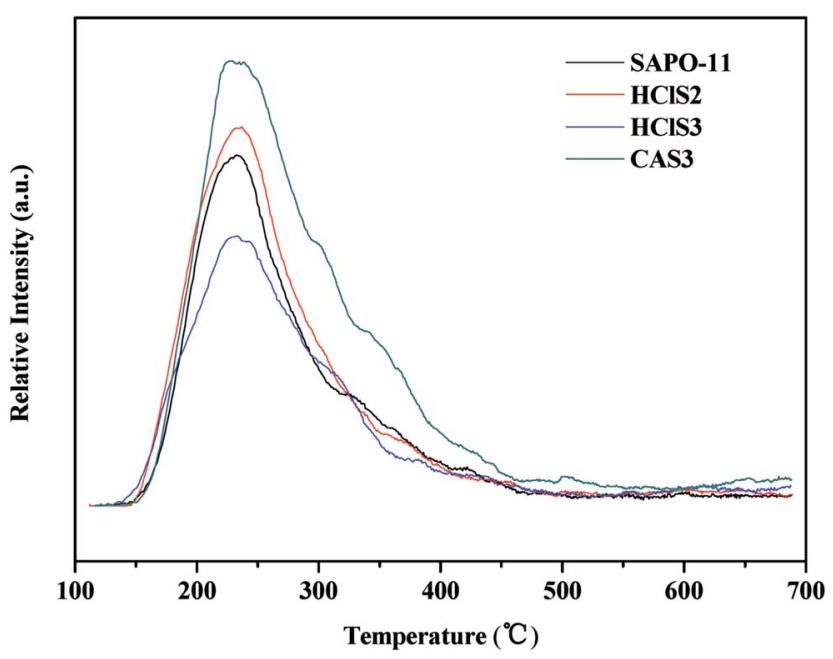

Fig. $5 \mathrm{NH}_{3}$-TPD results of SAPO-11, HCIS2, HCIS3, and CAS3. 

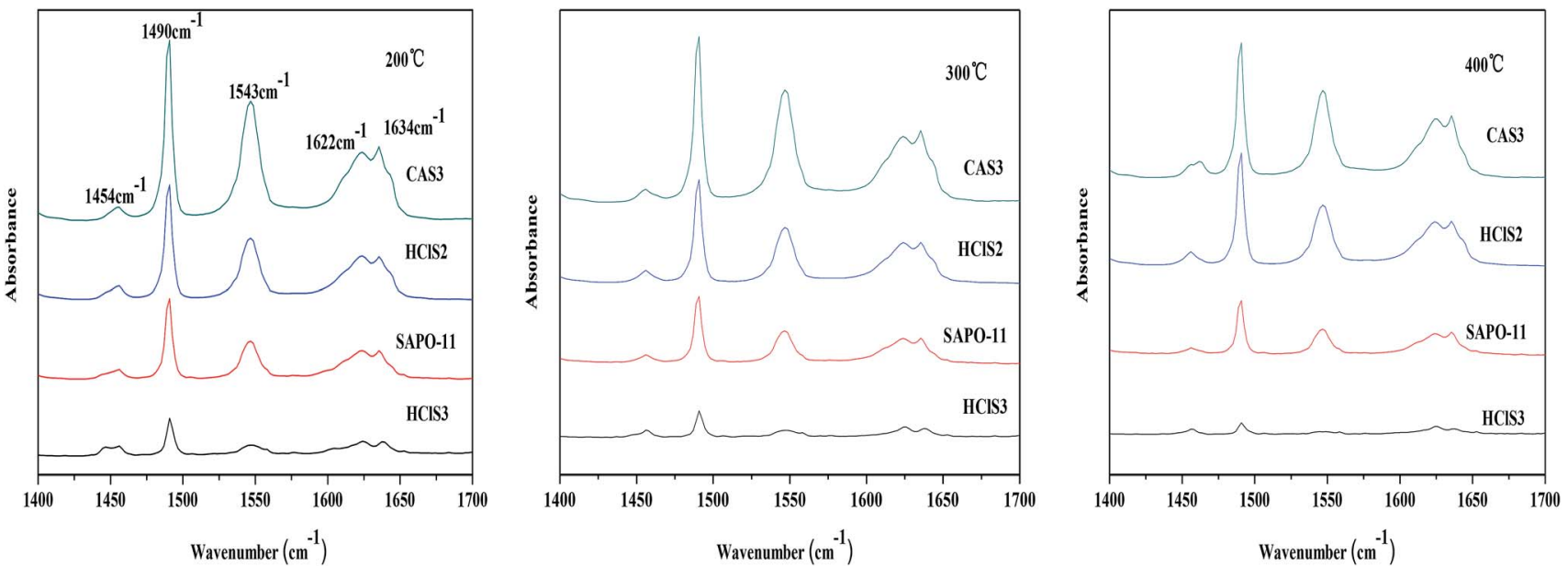

Fig. 6 Py-IR spectra of SAPO-11, HCIS2, HCIS3, and CAS3 obtained at different temperatures.

band at around $1490 \mathrm{~cm}^{-1}$ can be associated with pyridine adsorbed on both Lewis and Brönsted acid sites. ${ }^{18}$ The Py-IR spectra of SAPO-11, HClS2, HClS3, and CAS3 obtained at 200, 300 , and $400{ }^{\circ} \mathrm{C}$ are presented in Fig. 6. Both Lewis acid sites and Brönsted acid sites decrease in the following order: CAS3 > HClS2 $>$ SAPO-11 $>$ HClS3, which is in agreement with $\mathrm{NH}_{3}$-TPD results shown in Fig. 5. In addition, Lewis acid sites and Brönsted acid sites decrease in line with the increasing temperature as the amount of chemisorption is less at high temperatures than that at low temperatures.

3.1.6 ${ }^{29}$ Si MAS NMR. ${ }^{29}$ Si MAS NMR spectra of SAPO-11, HClS2, HClS3, and CAS3 are presented in Fig. 7. It is evident that the Si environments have significant effect on the acidity of SAPO molecular sieve, which is enhanced in the order: $\mathrm{Si}(4 \mathrm{Si})<$ $\mathrm{Si}(4 \mathrm{Al})<\mathrm{Si}(3 \mathrm{Al}, 1 \mathrm{Si})<\mathrm{Si}(2 \mathrm{Al}, 2 \mathrm{Si})<\mathrm{Si}(\mathrm{Al}, 3 \mathrm{Si}) .{ }^{19}$ As shown in Fig. 7 , there are five peaks at $-90,-100,-105,-108$, and $-112 \mathrm{ppm}$, induced by the $\mathrm{Si}(4 \mathrm{Al}), \mathrm{Si}(3 \mathrm{Al}, \mathrm{Si}), \mathrm{Si}(2 \mathrm{Al}, 2 \mathrm{Si}), \mathrm{Si}(\mathrm{Al}$, $3 \mathrm{Si})$, and $\mathrm{Si}(4 \mathrm{Si})$ environments, respectively. HClS3 shows an

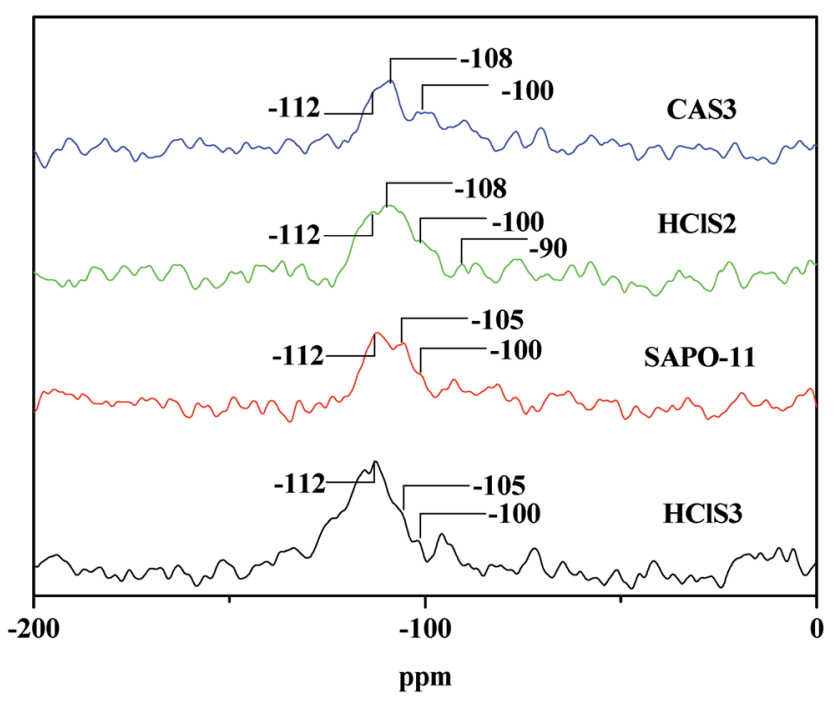

Fig. $7{ }^{29}$ Si MAS NMR spectra of SAPO-11, HCIS2, HCIS3, and CAS3. intensive peak at $-112 \mathrm{ppm}$ assigned to $\mathrm{Si}(4 \mathrm{Si})$ environments, which indicates that the number of acid sites of HClS3 is the least. CAS3 has the most abundant acid sites because of its intensive $\mathrm{Si}(\mathrm{Al}, 3 \mathrm{Si})$ environments (-108 ppm).

\subsection{Catalytic performance for the methylation of naphthalene}

The catalytic conversion and stability of SAPO-11, HCIS2, HClS3, and CAS3 are compared in Fig. 8. As shown in Fig. 8, the conversion of naphthalene to SAPO- 11 is $74.3 \%$ and $25.6 \%$ with $1 \mathrm{~h}$ and $6 \mathrm{~h}$ reaction times, respectively. The naphthalene conversion of HClS2 is $79.2 \%$ with reaction time of $1 \mathrm{~h}$, but decreases to $45.7 \%$ with reaction time of $6 \mathrm{~h}$. Conversion of naphthalene for HClS2 is $71.6 \%$ with reaction time of $1 \mathrm{~h}$ and $21.6 \%$ with reaction time of $6 \mathrm{~h}$. CAS3 has the highest conversion of naphthalene $(82.4 \%)$ with the reaction time of $1 \mathrm{~h}$, and the conversion of naphthalene is $30.8 \%$ with the reaction time

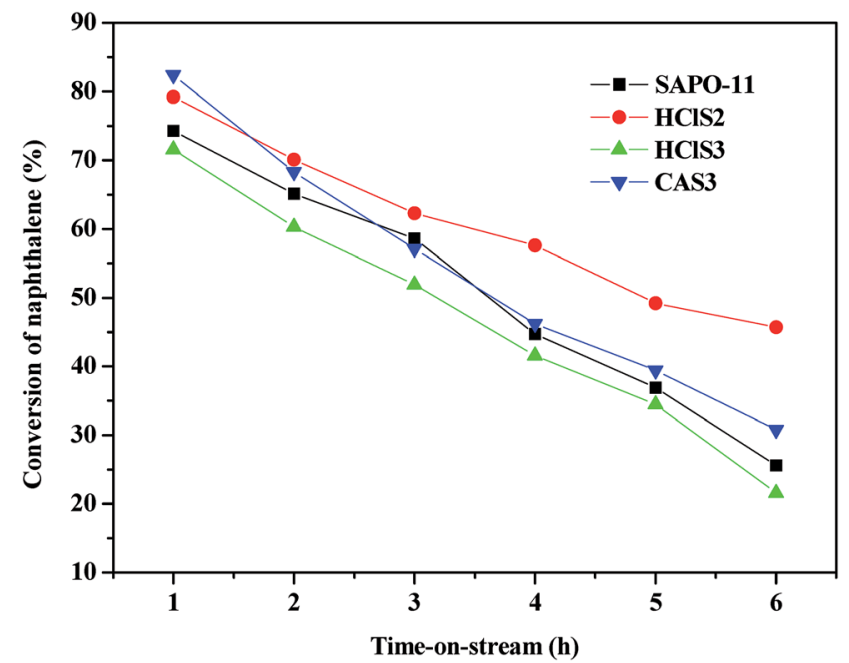

Fig. 8 The conversion of naphthalene over SAPO-11, HCIS2, HCIS3, and CAS3. 
Table 3 Comparison of catalytic performance of SAPO-11, HCIS2, HCIS3, and CAS3 for the methylation of naphthalene ${ }^{a}$

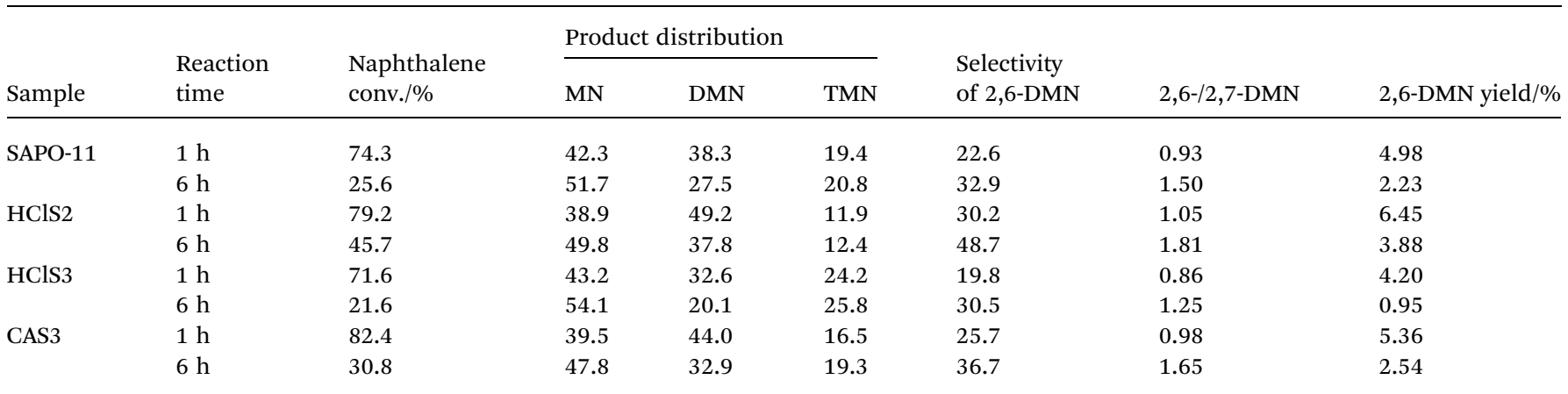

${ }^{a}$ Reaction conditions: temperature $=400{ }^{\circ} \mathrm{C}$, pressure $=0.1$ MPa, WHSV (based on naphthalene) $=0.19 \quad \mathrm{~h}^{-1}$, $n$ (naphthalene) $: n$ (methanol) $: n$ (mesitylene) $=1: 5: 3.5$ (molar ratio), time-on-stream $=1 \mathrm{~h}, 6 \mathrm{~h}$.

of $6 \mathrm{~h}$. The initial activity of CAS3 is higher than that of the other samples because it has more active centers than others due to its strong acidity. However, conversion of naphthalene does not decrease quickly although its strong acidity can accelerate the coke formation. On the contrary, HClS2 exhibits lower initial naphthalene conversion, and its stability is the highest among all the samples although its acidity is not the weakest. These results indicate that there is no correlation between naphthalene conversion and acidity of samples. As seen in Table 2 and Fig. 4, the secondary mesopore size distributions decreases in the following order: HClS2 > CAS3 > SAPO-11 > HClS3. Thus, an increase in second mesoporosity can lead to the introduction of more reactants into the major channels or can facilitate the products desorption out of the major channels, thus resulting in enhancement of conversion of naphthalene by HClS2. Therefore, the conversion of naphthalene is probably related to the differences in the pore structure of SAPO-11 samples, especially relating to the amount of secondary mesopores in the SAPO-11 molecular sieves. More number of secondary mesoporses in SAPO-11 molecular sieves result in the higher conversion of naphthalene over SAPO-11 samples. Moreover, it can be seen from Fig. 8 that the naphthalene conversion over SAPO-11, HClS2, HClS3, and CAS3 decreases with increased reaction time. It is possible that because some reactant molecules or intermediates are formed in the pore channels during the synthesis process, which block the pores of channels of SAPO-11 samples and prevent the further diffusion of the reactant and the product molecules, ${ }^{20}$ thus leading to lower naphthalene conversion at longer reaction times. Based on the abovementioned reason, the authors think that the naphthalene conversion increases with time because the pore size of SAPO-11 molecular sieves can be increased by modifying the synthetic method or modifying the SAPO-11 molecular sieves. ${ }^{21-23}$

The catalytic performance of SAPO-11, HClS2, HClS3, and CAS3 with $1 \mathrm{~h}$ and $6 \mathrm{~h}$ time on stream (TOS) are listed in Table 3. Table 3 shows that the main products are methylnaphthalene $(\mathrm{MN})$, dimethylnaphthalene (DMN), and trimethylnaphthalene (TMN). The 2,6-DMN yield over the investigated molecular sieves decreases in the order: HClS2 > CAS3 > SAPO-11 > HClS3. The selectivity of 2,6-DMN and 2,6-/2,7-DMN ratio decrease in the order: HClS2 $>$ CAS3 $>$ SAPO-11 $>$ HClS3 with the reaction time, which is not associated with the acidity of the samples. Fang et al. have calculated that 2,6-DMN is somewhat larger than 2,7-DMN in molecular dimension, ${ }^{24}$ with their molecular dimensions in length, thickness, and cylindrical diameter being 10.06 ̊, 2.76 ̊, $6.44 \AA$ for 2,6-DMN and $9.73 \AA$, $2.76 \AA$, $6.03 \AA$ for 2,7-DMN. Therefore, 2,6-DMN suffers more diffusion resistance than 2,7-DMN, diffusing out from the pore channel of SAPO-11. HClS2 exhibits broader pore size distributions than the other SAPO-11 samples (see Table 2 and Fig. 4). The broad pore size distributions are helpful for the diffusion of 2,6-DMN, particularly, for the generation of the secondary mesopores over HClS2; this makes them more favorable for the diffusion of 2,6-DMN, thus finally leading to higher selectivity of 2,6-DMN and 2,6-/2,7DMN ratio. Thus, SAPO-11 molecular sieves with more amount of secondary mesoporses present higher selectivity of 2,6-DMN and 2,6-/2,7-DMN ratio than other SAPO-11 samples.

\section{Conclusions}

SAPO-11 molecular sieves were modified by hydrochloric acid and citric acid. The influence of modification of SAPO-11 by the two acids on the acidity, pore structure, and catalytic performance of the modified SAPO-11 molecular sieve-supported catalysts for the methylation of naphthalene was investigated. The XRD results showed that the modification of SAPO-11 by hydrochloric acid and citric acid decreased the relative crystallinity of the sample without destroying the AEL topology of SAPO-11. $\mathrm{N}_{2}$ adsorption-desorption results showed that micropores and secondary mesopores were present in all samples. Moreover, $\mathrm{NH}_{3}$-TPD and ${ }^{29} \mathrm{Si}$ MAS NMR measurements showed that hydrochloric acid at a high concentration could eliminate more acid sites.

The treatment of SAPO-11 with $8 \mathrm{~mol} \mathrm{~L}^{-1}$ hydrochloric acid for $30 \mathrm{~min}$ (HClS3) not only removed some extra-framework aluminum of SAPO-11 but also deleted some framework silicon of SAPO-11; this resulted in lower degree of the secondary mesopores size, the total acid number, the conversion of naphthalene, and 2,6-DMN yield. SAPO-11 modified by $4 \mathrm{~mol} \mathrm{~L}^{-1}$ hydrochloric acid for $30 \mathrm{~min}$ (HClS2) showed the highest crystallinity, the broadest pore size distributions, and the highest catalytic performances among all the SAPO-11 samples modified in this study. 


\section{Conflicts of interest}

There are no conflicts to declare.

\section{Acknowledgements}

This work was supported by the National Science Foundation of Shanxi Province, China (201601D102011), the National Science Foundation for Young Scientists of Shanxi Province, China (2015021042), and the National Science Foundation for Young Scientists of Shanxi Province, China (201601D202016).

\section{References}

1 S.-B. Pu and T. Inui, Appl. Catal., A, 1996, 146, 305-316.

2 C.-S. Song and H.-H. Schobert, Fuel Process. Technol., 1993, 34, 157-196.

3 D. Fraenkel, M. Cherniavsky, B. Ittah and M. Levy, J. Catal., 1986, 101, 273-283.

4 J.-N. Park, J. Wang, C.-W. Lee and S.-E. Park, Bull. Korean Chem. Soc., 2002, 23, 1011-1013.

5 G. Pazzuconi, G. Terzoni, C. Perego and G. Bellussi, Stud. Surf. Sci. Catal., 2001, 135, 4071-4078.

6 X.-F. Bai, K.-Y. Sun, W. Wu, P.-F. Yan and J. Yan, Appl. Catal., $A, 2010,375,279-288$.

7 X.-X. Wang, F. Guo, X.-X. Wei, Z.-M. Liu, W. Zhang, S.-Q. Guo and L.-F. Zhao, Korean J. Chem. Eng., 2016, 33, 2034-2041.

8 X.-X. Wang, Z.-M. Liu, X.-X. Wei, F. Guo, P. Li and S.-Q. Guo, Braz. J. Chem. Eng., 2017, 34, 295-306.

9 B.-M. Lok, C.-A. Messina, R.-L. Patton, R.-T. Gajek, T.-R. Cannon and E. M. Flanigen, Crystalline silicoaluminophosphates, US Pat., 4440871, 1984.
10 C.-M. Song, Y. Feng and L.-L. Ma, Microporous Mesoporous Mater., 2012, 147, 205-211.

11 K. Yoo, E.-C. Burckle and P.-G. Smirniotis, J. Catal., 2002, 211, 6-18.

12 J.-N. Park, J. Wang, S. I. Hong and C. W. Lee, Appl. Catal., A, 2005, 292, 68-75.

13 X.-F. Bai, K.-Y. Sun, W. Wu, P.-F. Yan and J. Yang, J. Mol. Catal. A: Chem., 2009, 314, 81-87.

14 H. Najar, M.-S. Zina and A. Ghorbel, React. Kinet., Mech. Catal., 2010, 100, 385-398.

15 P. Mériaudeau, V.-A. Tuan, V.-T. Nghiem, S.-Y. Lai, L.-N. Hung and C. Naccache, J. Catal., 1997, 169, 55-66.

16 R. Giudici, H.-W. Kouwenhoven and R. Prins, Appl. Catal., A, 2000, 203, 101-110.

17 Q.-Y. Wu, I.-N. Oduro, Y. Huang and Y.-M. Fang, Microporous Mesoporous Mater., 2015, 218, 24-32.

18 P. Kalita, N.-M. Gupta and R. Kumar, J. Catal., 2007, 245, 338-347.

19 G. Sastre, D.-W. Lewis and C.-R.-A. Catlow, J. Phys. Chem. B, 1997, 101, 5249-5262.

20 N. Lucas, A. Bordoloi, A.-P. Amurute, P. Kasinathan, A. Vinu, W. Bohringer, J. C. Q. Fletcher and S.-B. Halligudi, Appl. Catal., A, 2009, 352, 74-80.

21 P. Liu, J. Ren and Y.-H. Sun, Chin. J. Catal., 2008, 29, 379384.

22 A.-K. Sinha, S. Seelan, S. Tsubota and M. Haruta, Top. Catal., 2004, 29, 95-102.

23 I. Eswaramoorthi and N. Lingappan, J. Mol. Catal. A: Chem., 2004, 218, 229-239.

24 Y.-M. Fang and H.-Q. Hu, Catal. Commun., 2006, 7, 264-267. 